\title{
An investigation of rapid warm transitions during MIS2 and MIS3 using Greenland ice-core data and the CLIMBER-2 model
}

\author{
Irene A. MOGEnSEN, ${ }^{1}$ Sigfús J. JOHnSEN, ${ }^{1}$ Andrey GANOPOLSKI, ${ }^{2}$ Stefan RAHMSTORF ${ }^{2}$ \\ ${ }^{1}$ Department of Geophysics, The Niels Bohr Institute for Astronomy, Physics and Geophysics, University of Copenhagen, \\ Fuliane Maries Vej 30, DK-2100 Copenhagen, Denmark \\ E-mail:iam@gfy.ku.dk \\ ${ }^{2}$ Potsdam Institute for Climate Impact Research, Telgrafenberg C4, P.O. Box 601203, D-14472 Potsdam, Germany
}

\begin{abstract}
In the search for a better understanding of the dominant mechanisms of the Earth's climate system, we present a study of rapid warm-climate transitions to DansgaardOeschger events as seen in the ice cores from the Greenland ice sheet. We present a continuous $\delta^{18} \mathrm{O}$ record from the Greenland Icecore Project (GRIP) core with a resolution of 5 years until $50 \mathrm{kyr}$ BP and of 20 years until $100 \mathrm{kyr}$ BP. These data are compared with other highresolution records, i.e. the Greenland Ice Sheet Project II (GISP2) chemistry record (25 years until $50 \mathrm{kyr} \mathrm{BP}$ ) and the GRIP $\mathrm{Ca}^{2+}$ record (3 years until $100 \mathrm{kyr} \mathrm{BP}$ ). All records have been transformed to the GISP2 Meese/Sowers time-scale. The high-resolution records are separated into interstadials and stadials, defined by the GRIP and GISP2 $\delta^{18} \mathrm{O}$ records. We examine in detail the transitions into the Dansgaard-Oeschger events, and propose a scenario for the changes that occur in the different ice-core records during the approximately 50 years the transition takes. The main difference from previous studies is the much higher-resolution datasets available until $50 \mathrm{kyr} \mathrm{BP}$; previous high-resolution studies by Taylor and others (1997) have focused on only the Younger Dryas/Preboreal transition. The data are compared to model simulations of the Dansgaard-Oeschger events performed with the CLIMBER-2 model of intermediate complexity (Petoukhov and others, 1998; Ganopolski and Rahmstorf, 2001).
\end{abstract}

\section{INTRODUGTION}

Dansgaard-Oeschger events are still a much-discussed topic within the palaeoclimate research community. More palaeodata are gradually building up a picture of the large, very rapid climate changes that took place some 24-30 times during the last glacial. Ocean sediment cores have helped to improve our understanding of the role of the oceans in these different climate changes. However, the dating is still inadequate for determining in what order the changes occurred.

We present here isotopic data from the two Greenland Summit ice cores, Greenland Icecore Project (GRIP; Dansgaard and others, 1993) and Greenland Ice Sheet Project II (GISP2; Grootes and others, 1993).

We present a continuous (GRIP) $\delta^{18} \mathrm{O}$ record with a resolution of 5 years going back to $50 \mathrm{kyr}$ BP and of 20 years until 100 kyr BP. The GRIP $\delta^{18} \mathrm{O}$ data are compared with other high-resolution records, i.e. the GISP2 chemistry record (25 years until $50 \mathrm{kyr} \mathrm{BP}$ ) and the GRIP Ca ${ }^{2+}$ record ( 3 years until 100 kyr BP). For purposes of comparison, all records are converted to the GISP2 Meese/Sowers time-scale.

The high-resolution records are separated into interstadials and stadials, defined by the GRIP and GISP2 $\delta^{18} \mathrm{O}$ records. The signal analysis performed will be compared to previous studies of the high-resolution Ca record from GRIP and the GISP2 ion records and the new high-resolution GISP2 $\delta^{18} \mathrm{O}$ record. The present study is generally based on much higher-resolution data than were used in previous studies dating back to 50 kyr BP (Mayewski and others, 1994; Fuhrer and others, 1999; Johnsen and others, 2001). Finally the data will be compared to model simulations of Dansgaard-Oeschger events performed by the CLIMBER-2 model (Petoukhov and others, 1998).

\section{ICE-GORE DATA}

The data used in this study originate from the two deep ice cores GRIP (Fuhrer, 1991; GRIP Project Members, 1993) and GISP2 (Grootes and others, 1993; Mayewski and others, 1997; GISP2-GRIP compendium volume from the Wolfboro Workshop, 1995 (Journal of Geophysical Research 102(C12), 1997)). The data have been sampled at very high resolution, making possible a detailed study of the transitions from stadials to interstadials and vice versa. Here we will focus mainly on the stadial-to-interstadial transitions.

Figure 1 shows the resolution of the raw data discussed in this paper. There are a few holes in the records which we have bridged by interpolation (see Mogensen, 2001). The raw data series were resampled at the resolution shown in Table 1 by using occasional minor over-sampling (Mogensen, 2001).

In order to be able to work with data from the two ice cores, the GRIP data have been converted to the GISP2 time-scale (also named GISP2 Meese/Sowers time-scale; Bender and others, 1994); for details on how this conversion was done see Mogensen (2001). This approach allows us to work with a greater number of continuous high-resolution 

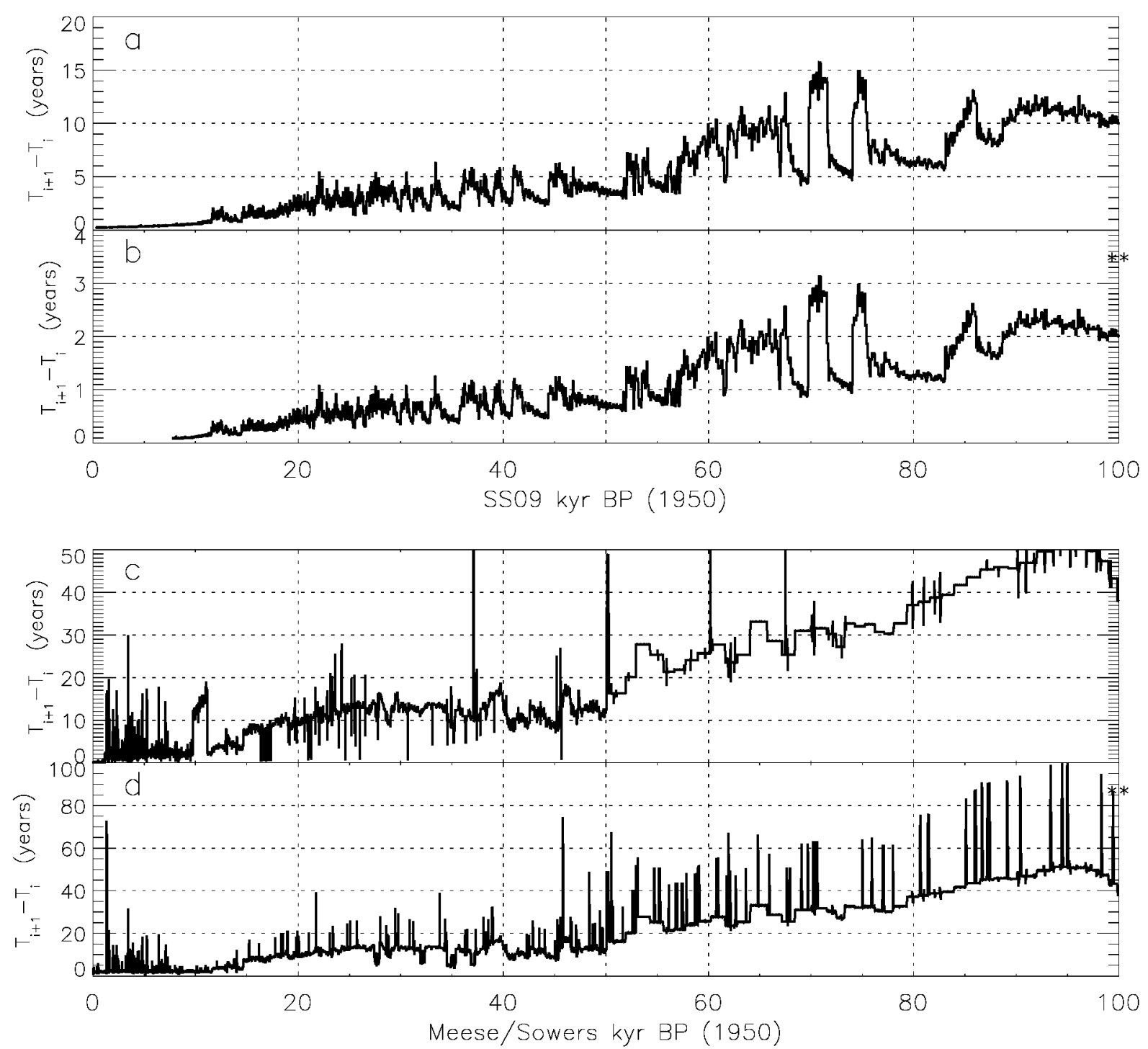

Fig. 1. The resolution of the raw data (sample size) used in this paper. (a) Sample size for the GRIP $\delta^{18} O$ record (Fohnsen and others, 1997); ( b) sample size for the GRIP calcium record (Fuhrer, 1995); (c) GISP2 sample size (Stuiver and Grootes, 2000); and (d) sample size of the GISP2 ion records (Mayewski and others, 1997).

datasets. The errors in the relative timing are dependent on the resolution and the noise of the data used to match the transitions in the two cores. The $\delta^{18} \mathrm{O}$ records used for matching the two records had a resolution of 20 years until 50 kyr BP and 50 years until 110 kyrBP for GISP2, and 20 years for the GRIP $\delta^{18} \mathrm{O}$ record. Hence we expect to "hit" the same event in the two records within 2-3 data points, i.e. $\sim 50$ years back to $50 \mathrm{kyr}$ BP and $\sim 150$ years for the rest of the record. Using higher resolution than 20 year averages for tying the two time-scales together results in too

Table 1. Resolution of the data series discussed in this paper Resolution until 50 kyr BP Resolution 50-100 kyr BP years years
$\operatorname{GRIP} \delta^{18} \mathrm{O}$

$\mathrm{GRIP} \mathrm{Ca}^{2+}$

GISP2 $\mathrm{Cl}$

GISP2 $\mathrm{Mg}^{2+}, \mathrm{Na}^{+}, \mathrm{Ca}^{2+}$

\section{0}

3

50 much noise for the method used, and would therefore not increase the "hit-rate" substantially.

We will first describe how the trend of the GRIP $\delta^{18} \mathrm{O}$ record and the trend of the GRIP Ca record correlate with the duration of the stadials and interstadials, respectively. We will then present the transitions at the onset of Dansgaard-Oeschger events. These very sharp transitions are easier to distinguish than the less sharp transitions from interstadials to stadials.

\section{METHODS}

The $\delta^{18} \mathrm{O}$ record in ice cores is the primary palaeo-data proxy for the Dansgaard-Oeschger events, and therefore has been chosen to define the onset and termination of these events. All the Dansgaard-Oeschger events (Dansgaard and others, 1993) were then located using the 20 year sampled $\delta^{18} \mathrm{O}$ datasets. The transition marks were placed at the steepest gradient for the onset and termination of each event. As tie points for transferring the GISP2 chronology to the GRIP records we used a total of 68 rapid transitions including all of the 48 DansgaardOeschger transitions.

To classify the Dansgaard-Oeschger events we deter- 


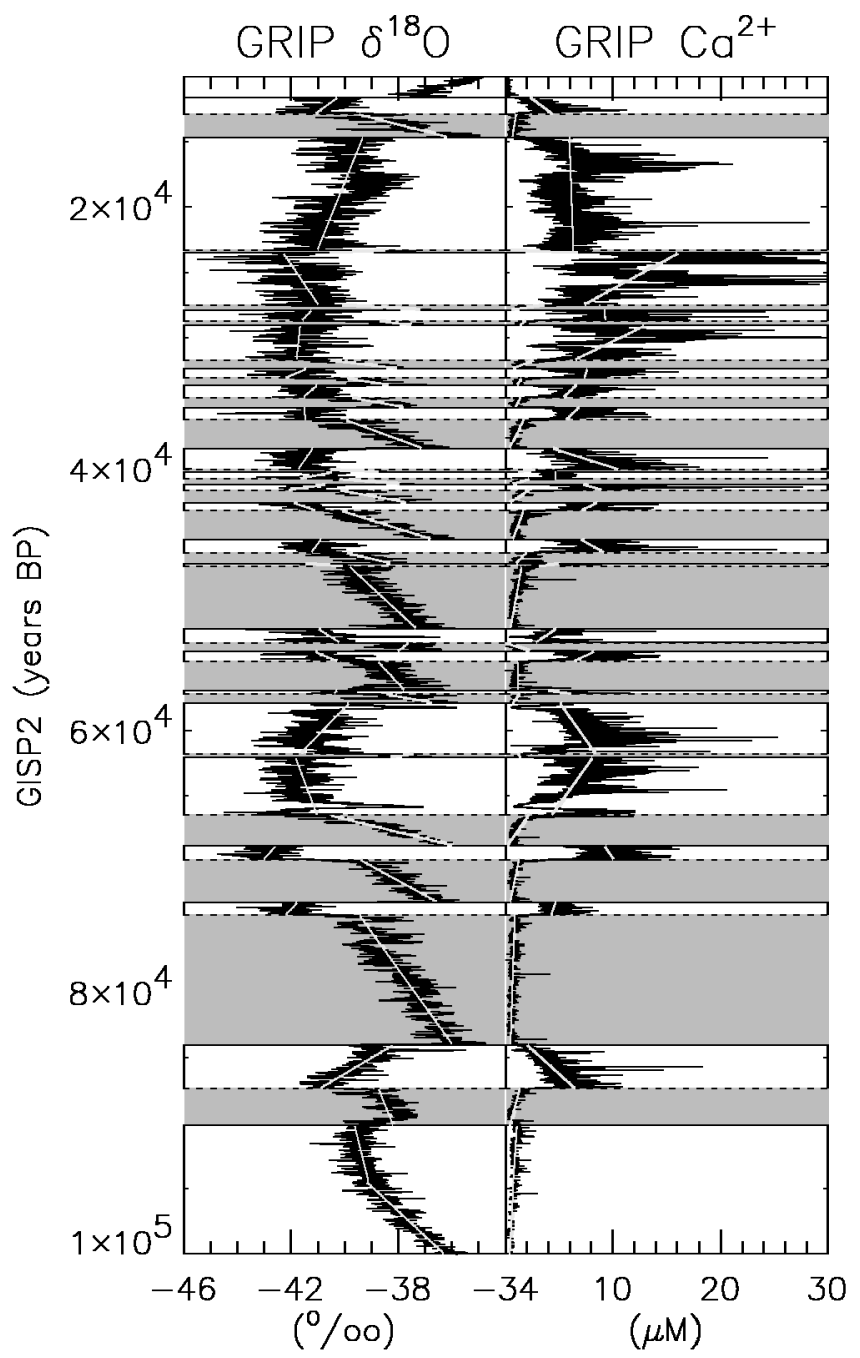

Fig. 2. The GRIP $\delta^{18} O$ record and calcium record for the last glacial. Warm periods are shaded and the linear segments for each interstadial and stadial are plotted in light grey.

mined the linear trends or slopes of the GRIP $\delta^{18} \mathrm{O}$ record and GRIP Ca record for each stadial and interstadial. Figure 2 shows the GRIP $\delta^{18} \mathrm{O}$ record and the GRIP Ca record and the linear segments found. We see that for most interstadials the trend for the $\delta^{18} \mathrm{O}$ record decreases with time (negative trends). For each sub-period of the entire Wisconsin glacial, the linear trend was plotted against the duration of the event (see Fig. 3). Figure 3a shows the relationship for the interstadials, and Figure $3 \mathrm{~b}$ for the stadials. We find that the shorter an interstadial is, the steeper is its trend in both $\delta^{18} \mathrm{O}$ and $\mathrm{Ca}$. The longest interstadials are found at the beginning of the last glacial, i.e. marine isotope stages $4,5 \mathrm{a}$ and $5 \mathrm{~b}$. The shorter events are found in marine isotope stage 3 , which is dominated by Bond cycles (Broecker, 1994) consisting of one long ( $>1000$ years) and 3-4 shorter Dansgaard-Oeschger events (few hundred years). Lastly, marine isotope stage 2 is dominated by the very long Last Glacial Maximum, perturbed by only two events, one of which is classified as a DansgaardOeschger event (GI-2, which lasts only about 300 years).

In Figure 3 a the trends for the calcium record almost mirror the $\delta^{18} \mathrm{O}$ trends. This agrees well with previous results, which detect a high anticorrelation between $\delta^{18} \mathrm{O}$ and $\mathrm{Ca}$ (GRIP Project Members, 1993; Mayewski and others, 1994; Fuhrer and others, 1999). For stadials the picture is somewhat more blurred, but the averaged trend for both $\delta^{18} \mathrm{O}$ and calcium is more or less zero.

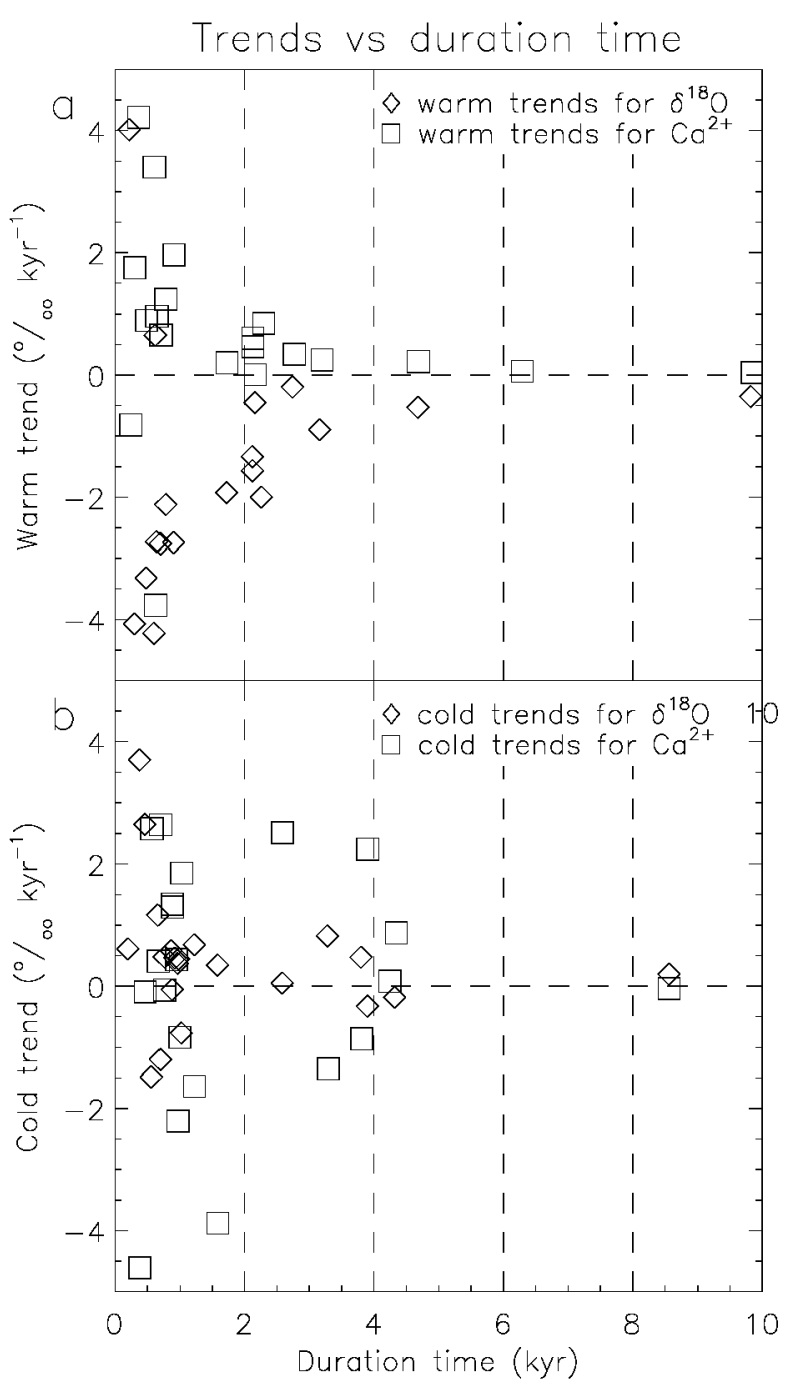

Fig. 3. The trends/slope of the linear segments shown in Figure 2, plotted against the duration of the corresponding event. (a) $\delta^{18} \mathrm{O}$ and calcium trends for the interstadials, and $(b) \delta^{18} \mathrm{O}$ and calcium trends for the stadials. It is clear that the strong anticorrelation between $\mathrm{Ca}$ and $\delta^{18} \mathrm{O}$ is very pronounced during the interstadials.

\section{RESULTS}

We present here a close-up of the 13 warm transitions from 10 to 50 kyr BP (Fig. 4), and discuss the averaged transition. This is compared to CLIMBER-2 model results of changes in Greenland temperature, deep Antarctic water in the Atlantic, North Atlantic Deep Water (NADW) formation, and the Nordic Seas salinity. The CLIMBER-2 model produces annual means for a variety of variables, and we have chosen those that are of most interest with respect to the ice-core data.

Figure $4 \mathrm{c}-\mathrm{f}$ show the 13 warm transitions that occurred from $10 \mathrm{kyr}$ BP to $50 \mathrm{kyr}$ BP, leaving out transition 1 (Wisconsin to Holocene). They show that the switch from stadial to interstadial takes about 50-70 years from the last cold value to the maximum. One large step seems to be taken during each transition, with a single jump in the $\delta^{18} \mathrm{O}$ values of 2.3\%o. Since the most rapid shifts in $\delta^{18} \mathrm{O}$ are used to define the transitions, we can expect to find this single jump in the averaged record as well. If one examines the $\delta^{18} \mathrm{O}$ values separately (not shown here) during a transition, there is a pronounced jump in the $\delta^{18} \mathrm{O}$ value in most transitions. Sometimes this jump is succeeded by a temporary drop in the $\delta^{18} \mathrm{O}$ value superimposed on the general transition climb. 

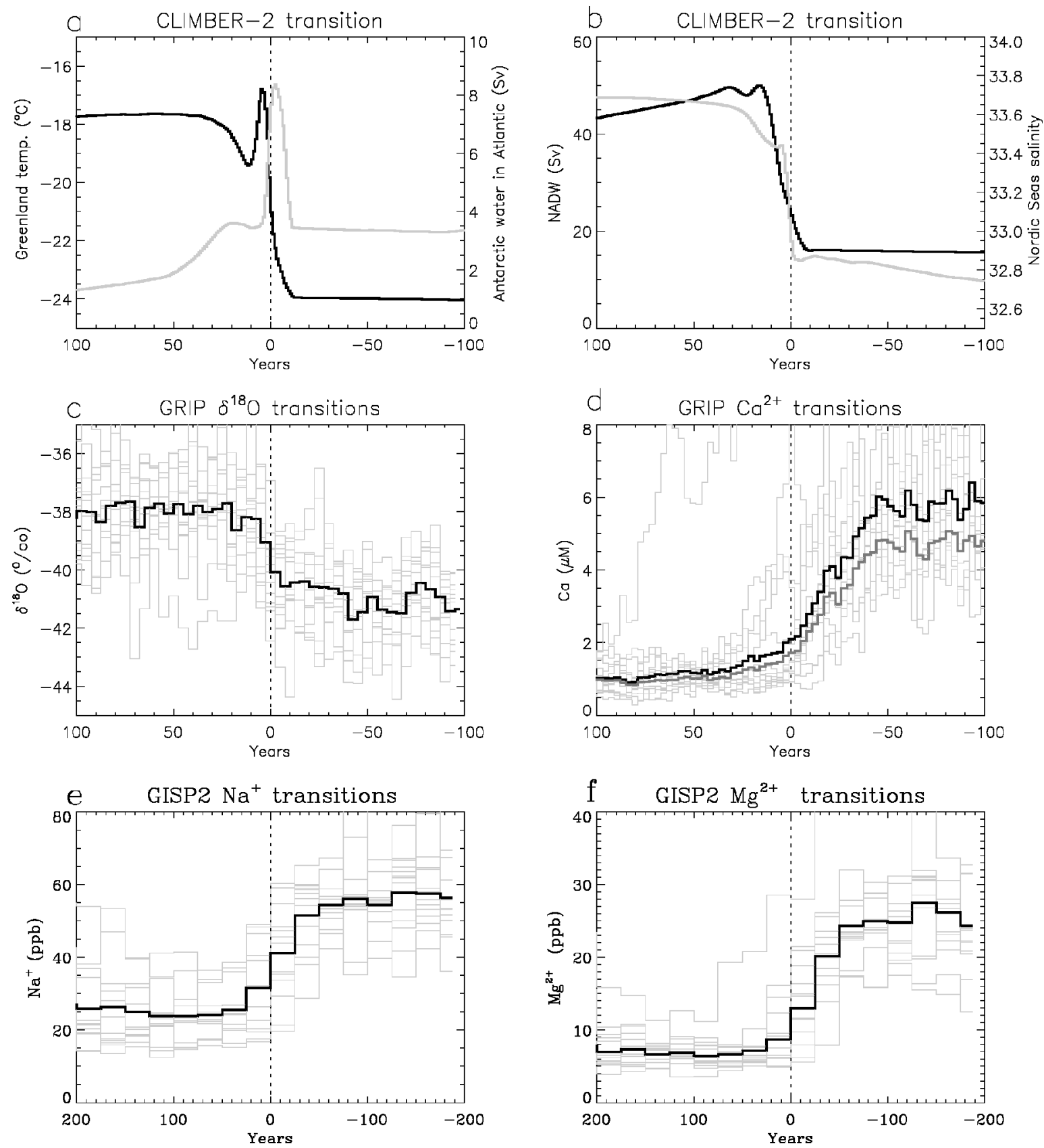

Fig. 4. (a) Five-year smoothed Greenland temperature and in grey the Antarctic water flow into the Atlantic. (b) Five-year smoothed North Atlantic Deep Water formation in Sv, and in grey the Nordic Seas salinity. (c-f) Shown in light grey are the 13 transitions to Dansgaard-Oeschger events from $50 \mathrm{kyr}$ BP for GRIP $\delta^{18} \mathrm{O}(\mathrm{c}), \mathrm{GRIP} \mathrm{Ca}^{2+}(d), \mathrm{GISP}_{2} \mathrm{Na}^{+}$(e) and GISP2 $\mathrm{Mg}^{2+} .(f)$ The averages of these transitions are shown in black.

If we compare the CLIMBER-2 Dansgaard-Oeschger transitions and the ice-core data, as done in Ganopolski and Rahmstorf (2001) (Fig. 4b), we see some striking similarities. The model variables are 5 year averages, and Figure 4a and b show a Dansgaard-Oeschger transition spanning 200 years, as for the GRIP data. The variables shown were chosen because they all show clear changes through a transition. The model was forced with a sinusodial fresh-water flux into the North Atlantic region, as was done in the Ganopolski and Rahmstorf (2001) study. Our forcing did not, however, include the strong fresh-water pulse introduced by Ganopolski and Rahmstorf to simulate a Heinrich event. Figure 4 a shows the Greenland temperature shift and the amount of Antarctic deep water that enters the Atlantic. The CLIMBER-2 Greenland temperature bears a fair resemblance to the Greenland $\delta^{18} \mathrm{O}$ profile (Ganopolski and Rahmstorf, 2001). The Antarctic deep water entering the Atlantic is also shown, since this variable precedes the temperature shift in Greenland. It is not possible to trace directly the Antarctic deep water inflow in the Greenland ice-core data. We do see that the initial drop in calcium precedes both the jump in $\delta^{18} \mathrm{O}$ and the onset of the influx of Antarctic water. This is most likely due to an artefact in the averaged $\mathrm{Ca}$ data as discussed below.

The early influx of Antarctic deep water in the CLIMBER-2 model is in agreement with data from ocean sediment cores off the coast of Portugal, which show that Antarctic bottom water flows into the Atlantic before the DansgaardOeschger events (Shackleton, 2001). Figure 4b shows the modelled NADW flux and the Nordic Seas salinity. On entering the interstadial the NADW formation is restored, and the salinity of the Nordic Seas increases, as the occurrence of con- 
vection shifts from south of Iceland to north of Iceland (Ganopolski and Rahmstorf, 2001). In the CLIMBER-2 output the transition to an interstadial is quicker than shown in the $\delta^{18} \mathrm{O}$ data. This is probably due to the atmospheric model's very rapid reaction to changes in ocean conditions.

The onset of the thermohaline circulation decreases the meridional temperature and pressure gradient, which again decreases the zonal winds in CLIMBER-2 (not shown). This should lead to a rapid fall in the calcium concentrations, which is not mirrored in the more slowly changing calcium data.

The Ca record (Fig. 4d) does not show the same large jumps as the $\delta^{18} \mathrm{O}$, even though it is often suggested that dust $/ \mathrm{Ca}^{2+}$ reacts faster to shifts in the climate system (e.g. transition 1, where the dust reaches Holocene values in only 20 years, whereas it takes the $\delta^{18} \mathrm{O}$ record about 50 years (Dansgaard and others, 1989)).

The Ca record could be influenced by larger noise, which smooths any sharp transition when making an averaged record. Indeed, in the individual transitions (shown in grey) we do see in some cases a pronounced step right around or before the $\delta^{18} \mathrm{O}$ step (this can be seen for individual transitions, i.e. Fuhrer and others (1999) and Figure 4b and c (Dansgaard and others, 1984)). Also the sodium and magnesium transitions are smoother than the $\delta^{18} \mathrm{O}$ record. Sodium is usually considered a proxy for the sea salts in the ice, and magnesium and calcium are considered tracers for land dust blown onto the ice.

The smooth transitions in the sodium and magnesium records may originate from imprecise tie points between the two ice-core records. Similar tie-point errors may also help explain why the averaged GRIP calcium record is even smoother in the transition even though some transitions in the calcium record are quite sharp (Fuhrer and others, 1999).

\section{CONGLUSION}

We have here used high-resolution ice-core data and the CLIMBER-2 model to investigate in detail what happens during the rapid warming transitions to DansgaardOeschger events.

In Figure 4, GRIP calcium, GISP2 sodium and magnesium all show a decrease prior to the large $\delta^{18} \mathrm{O}$ jump. We consider this early decrease to be an artefact of the averaged ionic data. We conclude that weakening of the atmospheric circulation (zonal wind speed) (Mayewski and others, 1997) leading to the drop in ionic concentrations most likely occurs in phase with the isotopic shifts in Greenland. This conclusion is supported by the CLIMBER-2 model runs presented here. The CLIMBER-2 model runs show even faster shifts into a Dansgaard-Oeschger event than are evidenced by the $\delta^{18} \mathrm{O}$ data.

\section{ACKNOWLEDGEMENTS}

This work is a contribution to the Greenland Icecore Project (GRIP) and was supported by a grant from the Danish Natural Science Research Council. We thank E. Steig and N. N. for most helpful comments.

\section{REFERENGES}

Bender, M. and 6 others. 1994. Climate correlations between Greenland and Antarctica during the past 100,000 years. Nature, 372(6507), 663-666.

Broecker, W. S. 1994. Massive iceberg discharges as triggers for global climate change. Nature, 372(6505), 421-424.

Dansgaard, W. and 6 others. 1984. North Atlantic climatic oscillations revealed by deep Greenland ice cores. In Hansen, J. E. and T. Takahashi, eds. Climate processes and climate sensitivity. Washington, DC, American Geophysical Union, 288-298. (Geophysical Monograph 29, Maurice Ewing Series 5.)

Dansgaard, W., J.W. C. White and S. J. Johnsen. 1989. The abrupt termination of the Younger Dryas climate event. Nature, 339(6225), 532-534

Dansgaard, W. and 10 others. 1993. Evidence for general instability of past climate from a 250-kyr ice-core record. Nature, 364(6434), 218-220.

Fuhrer, A. 1995. Ein System zur Messung des totalen Karbonatgehaltes polarer Eisproben. (Diplomarbeit, Universität Bern. Physikalisches Institut.)

Fuhrer, K. 1991. Messung der Ammonium und $\mathrm{H}_{2} \mathrm{O}_{2}$-Konzentracion in polaren Eis mit der Flow-Injection-Methode und $\delta^{18} \mathrm{O}$-Bestimmung an $\mathrm{H}_{2} \mathrm{O}_{2}$. Bern, Universität Bern. Physikalisches Institut.

Fuhrer, K., E. W. Wolff and S. J. Johnsen. 1999. Timescales for dust variability in the Greenland Ice Core Project (GRIP) ice core in the last 100,000 years. F. Geophys. Res., 104(D24), 31,043-31,052.

Ganopolski, A. and S. Rahmstorf. 2001. Rapid changes of glacial climate simulated in a coupled climate model. Nature, 409(6817), 153-158.

GRIP Project Members. 1993. Climate instability during the last interglacial period recorded in the GRIP ice-core. Nature, 364(6434), 203-207.

Grootes, P. M., M. Stuiver, J.W. C. White, S. Johnsen and J. Jouzel. 1993. Comparison of oxygen isotope records from the GISP2 and GRIP Greenland ice cores. Nature, 366(6455), 552-554.

Johnsen, S. J. and 14 others. 1997. The $\delta^{18} \mathrm{O}$ record along the Greenland Ice Core Project deep ice core and the problem of possible Eemian climatic instability. F. Geophys. Res., 102(C12), 26,397-26,410.

Johnsen, S. J. and 8 others. 2001. Oxygen isotope and palaeo-temperature records from six Greenland ice-core stations: Camp Century, Dye-3, GRIP, GISP2, Renland and NorthGRIP. 7. Quat. Sci., 16(4), 299-307.

Mayewski, P. A. and 13 others. 1994. Changes in atmospheric circulation and ocean ice cover over the North Atlantic during the last 41,000 years. Science, 263(5154), 1747-1751.

Mayewski, P. A. and 6 others. 1997. Major features and forcing of high-latitude Northern Hemisphere atmospheric circulation using a 110,000year-long glaciochemical series. F. Geophys. Res., 102(C12), 26,345-26,366.

Mogensen, I. A. 2001. A study of rapid climate change, Dansgaard-Oeschger events. (Ph.D. thesis, University of Copenhagen.)

Petoukhov, V. and 6 others. 1998. CLIMBER-2: a climate system model of intermediate complexity. Part I. Model description and performance for present climate. Potsdam, Potsdam Institute for Climate Impact Research (PIK).

Shackleton, N. 2001. Climate change across the hemispheres. Science, $291(5501), 58-59$.

Stuiver, M. and P. M. Grootes. 2000. GISP2 oxygen isotope ratios. Quat. Res., 53, 277-284.

Taylor, K. G. and 12 others. 1997. The Holocene-Younger Dryas transition recorded at Summit, Greenland. Science, 278(5340), 825-827. 